of this pilot project will be replicated in the remaining hot spots in order to expand ARVDs to the most unreachable populations.

\section{P6.024 THE TRIALS \& TRIBULATIONS OF CONDUCTING COMMUNITY BASED RESEARCH (CBR) ON SEXUAL HEALTH IN ABORIGINAL COMMUNITIES: THE ATLANTIC CANADA EXAMPLE}

doi:10.1136/sextrans-2013-051184.1178

\begin{abstract}
'A Steenbeek, 'C Aube, ${ }^{2 \top}$ Khattar. 'Dalhousie University, Halifax, NS, Canada;
\end{abstract} ${ }^{2}$ Healing Our Nations, Dartmouth, NS, Canada

Introduction Little is known about the sexual health needs that exist for many Aboriginal First Nations communities. As such, it is imperative that communities are given the opportunity to engage effectively in community-based research (CBR) and be involved in the planning, implementation and evaluation of sexual health policies/programmes from inception. Within this backdrop however, are Aboriginal communities ready and/or able to engage in CBR?

Objective The primary objective of our intended study was to identify and prioritise the sexual health needs of local First Nations Aboriginal communities (Mi'Kmaq and Malaseet) in Atlantic Canada through the use of an online needs assessment questionnaire.

Method Self identified Aboriginal Community members between the ages of 15-65, from seven First Nations were recruited to participate in a confidential/anonymous, online questionnaire through the Dalhousie University OPINIO web-based interface. The questionnaire was developed and validated with four First Nations Communities in Phases one and two of the project and, was also available as a hard copy for those not having computer access. Promotion of the survey was done through posters and word of mouth at the Community Health Centres and, through flyers. A draw incentive of fifty- dollar gift certificates was also offered to participants. Once collected the data was going to be used to help communities identify and prioritise sexual health needs to ensure better appropriation of sexual health services.

Results Despite aggressive and repeated recruitment strategies, only 132 surveys (electronic and hardcopy) from a prospective sample of 2003 community members meeting the inclusion criteria (combined 7 communities) were collected, giving a response rate of $6.5 \%$. Due to limited sample size, there were no meaningful results obtained.

Conclusion There are several lessons learned about engaging Atlantic Aboriginal First Nations communities in sexual health research that will be explored in the body of this report.

\section{P6.025 THE BRAZILIAN EXPERIENCE IN THE JOINT CONSTRUCTION OF ACTION PLANS FOR THE PREVENTION, CONTROL, SURVEILLANCE, DIAGNOSIS AND TREATMENT OF STDS, AIDS AND VIRAL HEPATITIS AMONG INDIGENOUS POPULATIONS}

doi:10.1136/sextrans-2013-051184.1179

L do Nascimento, N Fernandes, H Monteiro, E Santos, R Coelho, A Mello, V Costa, G Casimiro, E Zita, I Brito. Department of STDs, AIDS and Viral Hepatitis - Ministry of Health, Brasilia, Brazil

Background Within the Brazilian context, it is possible to say that indigenous populations are among the groups at highest risk and vulnerability to HIV, AIDS and viral hepatitis (VH). With the objective of reversing this situation, in 2009, the AIDS SUS and VIGISUS Projects were set up to improve STD/AIDS/VH interventions among these populations. In 2012, the Ministry of Health $(\mathrm{MoH})$ promoted the mobilisation of indigenous representatives of 34 Indigenous Health Sanitary Districts and healthcare professionals and administrators from all states.
Methods The Special Office for Indigenous Health and the MoH's Department of STDs, AIDS and VH conducted 6 macro-region workshops with the purpose of expanding and integrating the indigenous health network and strengthening infection control measures for STDs, AIDS and VH. Each workshop of 45 participants was held in a strategic state capital for 4 days. The methodology used interactive lectures, video, and round table meetings to discuss the current scenario and to jointly develop Action Plans that will target indigenous populations living in tribal or urban areas through 2015.

Results The organisation of the workshops integrated a broad spectrum of the various fields. Attendance averaged $71 \%$. During the events, reports documented the need for: training campaigns, exchange of information, a joint delineation of activities, and participation of indigenous representatives. The action plan's model comprises five core areas: prevention, reduction of vertical transmission, expansion of diagnosis, epidemiological surveillance, and treatment.

Conclusions The work was crucial for bringing together the various levels of government and actors involved in the formulation and operationalization of policies for indigenous populations. In 2013, the following will be conducted: monitoring, 3 evaluation workshops and visits to the tribes. The project is also expected to facilitate the participation of these populations in the construction of policies and services that meet and respect their specific cultural requirements.

\section{P6.026 LACK OF INTEGRATION OF PMTCT SERVICES AND MATERNAL SYPHILIS SCREENING AND TREATMENT IN MWANZA CITY-TANZANIA}

doi:10.1136/sextrans-2013-051184.1180

${ }^{1} \mathbf{R}$ Balira, ${ }^{2,3} \mathrm{D}$ Watson-Jones, ${ }^{3} \mathrm{D}$ Mabey, ${ }^{3} \mathrm{D}$ A Ross, ${ }^{3} \mathrm{H}$ Weiss. ${ }^{1}$ National Institute for Medical Research, Mwanza, Tanzania; ${ }^{2}$ Mwanza Intervention Trials Unit, Mwanza, Tanzania; ${ }^{3}$ London School of Hygiene and Tropical Medicine, London, UK

Background Integration of PMTCT and maternal syphilis screening and treatment is an efficient and cost-effective way of providing services to women at the point of delivery because it saves resources and providers' and clients' time. We documented the extent of integration of PMTCT and antenatal clinic (ANC) syphilis screening services in Mwanza city.

Methods Interviews were conducted with 89 health workers in 3 ANCs and in two maternity wards to collect information on key work activities, PMTCT training and syphilis management. Observations were made by the research team on 9 health education sessions, the client flow in ANCs and on the care of women admitted for delivery and who were not screened for syphilis during pregnancy.

Results Only $25 \%$ of ANC and maternity ward health workers had received training in both PMTCT and syphilis management. Generally, women attending for the first ANC visit for that pregnancy spent $\geq 3$ hours at the clinic. The maximum distance covered within the facility while accessing services in the ANCs was $0.3 \mathrm{~km}$. At one of the three ANCs, there was no PMTCT and syphilis service integration.

All women who were not screened for syphilis at ANCs were not offered any screening at the maternity ward. In contrast $70 \%$ of women who had not been screened for HIV in pregnancy were screened at delivery

Conclusion Both PMTCT and maternal syphilis screening and treatment services are documented policies in Tanzania. However, the absence of integrated guidelines and protocols regarding syphilis screening within PMTCT services is a challenge for ANC and maternity ward service providers.

Health workers at all levels of maternal care should be given training on implementation of integrated services for both prevention of syphilis and MTCT of HIV. 